\title{
A Study of Life Education Creative Poster Design Competition
}

\author{
Rui-Lin Lin \\ Department of Commercial Design \\ Chienkuo Technology University \\ No. 1, Chieh Shou N. Rd., Changhua City 500, Taiwan \\ email: linrl2002@gmail.com
}

\begin{abstract}
This study integrated the teaching and learning processes of a creative design curriculum into the Life Education Creative Poster Design Competition held by the Ministry of Education, with the students from Class B of the first grade in a Technology University who entered the university in 2012 as the research subjects. The teacher inspired the students' creative ideas through the creative thinking and designing methods regarding arrangements of pictures and texts, and discussed with the students about the modifications of their works through the individual discussion method. The more representative works were selected and submitted to the competition based on the evaluation criteria. As for the competition achievements, the team won a third place award and an honorable mention.
\end{abstract}

Keywords-life education; innovative poster, design competition

\section{INTRODUCTION}

Life is a supreme miracle. Individuals tend to value lives and consider lives as divine. They believe lives are spiritual with the highest values. Life education is an activity with values regarding teaching individuals to understand, appreciate, and cherish themselves, while respecting others. Lives and education are closely related. Lives are the root of education, and education is the motive power of lives. Through education, individuals can bring out their potentials and make their lives more valuable. The purpose of life education is to help individuals to, in the process of being educated, not only learn the knowledge and skills required for lives, but also cultivate richer lives, in order to become useful and happy individuals in the society [4, 2].

Life education includes: (1) the cognitive level: learning and understanding the meanings and values of bodies and lives, getting familiar with the principles of getting along with others, and knowing the methods to cherish lives of others and oneself; (2) the practical level: actually practice without depreciating or hurting others or oneself; and (3) the emotional level: continuously introspecting and appreciating lives of others and oneself. In the aspect of content, individuals can explore and pursue the meanings, goals, and ideals of lives, and develop mature moral thinking and ability to choose what is good, to internalize and practice cognition, emotion, and volition. The fundamental concepts of the content of life education are: (1) education of self-respect: ask for others' opinions before asking for help; (2) education of conscience: an individual's internal conscience feelings; (3) education of free will: an individual's behaviors based on his own rationality; and (4) education of self-other relation: individuals depending on each other, not being able to live alone [2].

The Life Education Creative Poster Design Competition which this study participated in was held by the Ministry of Education, with the purpose of inspiring the attitude of respecting lives and loving lives of school teachers and students and the general public, to create caring, friendly, trusting, and loving atmosphere in campuses and the society. Each participant could submit only one work. The awards included one first-place prize, one second-place prize, onethird place prize, and 5 honorable mentions. Winners were awarded monetary prizes and certificates.

\section{LITERATURE REVIEW}

\section{A. Life Education}

The characteristics of life education include uniqueness and complexity. When it comes to education, it is necessary to care about development of mental health from the viewpoint of individuals, and define a unique method to treat people with people being the starting point. One's life belongs to oneself. It cannot be replaced by others. The core characteristic of life education is openness of minds of teachers and students, so that content and definition of lives can be continuously developed and generated. In other words, content of lives is open. Individuals have the right to choose how their lives are presented, but no right to dominate others' lives. In a process of life education, teachers must keep their minds open to avoid the phenomenon of domination. They have to play the role of learning facilitators, in order to provide students chances to learn, to build open mechanisms for learning, and to guide individuals to follow virtues and make progress in learning. Secondly, activeness of teaching means both teachers and students should get involved actively. They are both active in a life education process. They devote themselves into a teaching situation with sincere and touching hearts to communicate with each other psychologically [3].

Life education aims to help individuals to discover meanings and development of their lives. The general life education goals include (1) systematically regulating and managing contents and ranges through courses; (2) integrating learning spirits from various subjects, (3) participatory team teaching, (4) teaching of life education related issues through teachers' examples, (5) schools placing importance on life education reformation for the main focus 
of life education is on experiential education; and (6) longterm implementation of life education. In a narrow sense, life education is to understanding the meanings of life and death of human beings, develop individuals' proper attitudes and responding skills regarding facing and learning life and death, and help individuals to develop proper life views. The principles of implementation are to know well keys of development, content of life attitude learning, and learning methods of life values in different phases, to respect individuals' unique experiences and emotions, and to accept different values. The teaching methods include: (1) introspection, (2) role playing, (3) group discussion, (4) team discussion, (5) debate, (6) creation, (7) report, (8) check list, (9) visit, interview, or field survey, (10) experimental activity, (11) metaphor, and (12) story [9].

\section{B. Related Research}

Some scholar believed that life education is cross-field and is highly related to individuals' ages [6]. Also there was a scholar using higher education as an example to study life education, believing that learning content of professional curriculums can be integrated, through the method of imperceptible influence, to guide students to respect the value of life and put it into practice, so that they can adapt various living environments and face and overcome various difficulties. Especially, when they feel frustrated in learning professional design ability, they can respond with an attitude of not being afraid of difficulties [7].

Furthermore, it is found that, in the recent years, university students have gradually started to lose respect for life. Therefore, the resources of internet information communication were used, and the more constructive ones related to life education issues were integrated through video media, in hopes of delivery the unique meanings and values of life education via carefully selected movies, in order to encourage students to respect life, cherish life, build a healthy and active life attitude, develop harmonic relationships with others and environments, and eventually achieve their own values [10]. Also there was a scholar exploring the life education issues with secondary and elementary school students and believing that it is essential to provide them basic safety education content and defending strategies, to create awareness of preventing physical and psychological harm [8].

\section{INNOVATIVE POSTER DESIGN}

The purposes of creative thinking teaching are to inspire students' motivation to create, encourage their creative performances, and facilitate development of their creativity. Creative thinking teaching method is a teaching method that, in a teaching and learning process, a teacher follows the principles of cultivating creativity to arrange reasonable and efficient teaching scenarios and attitudes, through diversified and vigorous course contents, teaching activities, and learning scenarios stimulates students so that they can think while learning, and facilitates their creative thinking abilities of making something out of nothing and making something new out of something. This study explored the issues related to the Life Education Creative Poster Design Competition, hoping that the students could also realize the importance of cherishing life and that life is priceless during their participation in the competition [5].

\section{A. Meanings and Principles}

The teacher had to encourage the students to use their imagination to improve their creative thinking abilities. And in the learning activities, the subjects were the students. They could freely imagine and express their opinions and views. Also, the teacher provided free, safe, and harmonic scenarios and atmosphere of discussions. The teaching methods focused on the students' interests, tolerating their different opinions, and making no rush judgments. From the aspect of learning, creative thinking teaching is about thinking and problem-solving. The essence of creation is smooth, unique, flexible, and of high quality.

The teaching principles of creative thinking teaching include: in the emotional aspect, developing students' curiosity, imagination, and characteristics of not being afraid of difficulties, brave to express themselves, and glad to make breakthroughs; and in the intellectual aspect, improving students' sensitivity and increase thinking creativity. Generally, the principles are: (1) providing a diversified, open, and supportive environment, (2) accumulating knowledge base to come up with new ideas, (3) holding specific, workable, vigorous, and interesting activities to combine creativity and life and improve abilities to solve problems, (4) teaching thinking techniques which are naturally integrated into courses, (5) considering both divergent and convergent thinking, and emphasizing both critical and creative thinking, (6) cooperating and learning as a team and making exchanges of heterogeneous creative ideas, (7) combining family and social resources with diversified development of wisdom, (8) applying diversified evaluation and recording creative ideas any time, (9) starting new conception while considering ethics of creativity, and (10) enhancing teachers' teaching introspection and students' meta-cognition [5].

\section{B. Activities and Teaching}

The purpose of school education is to develop students' ability of independent thinking. And thinking is the process of mind activities, and is a type of mind ability. Different types of thinking which can be applied include: (1) vertical thinking and horizontal thinking, (2) positive thinking and negative thinking, (3) associative thinking and directive thinking, (4) convergent thinking and divergent thinking, (5) algorithmic thinking and heuristic thinking and heuristic thinking, (6) cause-effect thinking and non-cause-effect thinking, and (7) dichotomous thinking and multidimensional thinking.

The teaching principles of improving thinking abilities: (1) encouraging students to think with flexibility, (2) encouraging students to think positively, (3) encouraging students to do systematic and directed thinking, (4) teaching students to do divergent thinking, (5) teaching students not to do heuristic thinking, and (6) encouraging students to think attentively before making any judgments regarding an issue. And factors which may influence problem-solving include: 
(1) misconception, (2) prejudice, (3) functional fixedness, (4) mental set, and (5) cognitive style [1].

\section{Design Results}

This study provided several cases regarding cherishing life as references for the students to design creative posters. And through the contents of the stories, the meaning of life was addressed, so that they could design their works with the understanding of how valuable life is. Secondly, the creative posters were scored according to their (1) theme (40\%), (2) creativity (30\%), and (3) color arrangement (30\%). More representative works were selected for the competition. And the achievements included that the poster in figure 1 won the 3rd place and the one in figure 2 won the honorable mention. The prizes were $\$ 8,000$ and $\$ 3,000$, respectively, both with a certificate of merit. These achievements show that teachers can consider more about choosing competitions with themes matching their curriculums more when integrating these competition themes into their curriculums as subjects for creation, and make better planning. Also, they can inspire students' willingness and motivation to participate in competitions, increasing their confidence in learning.

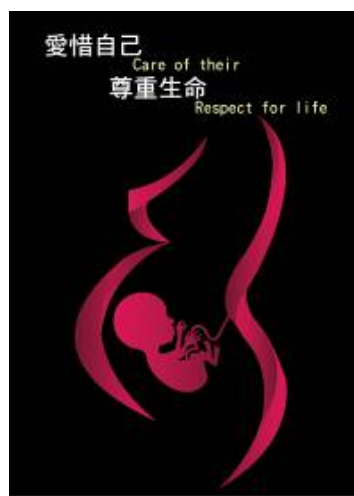

figure 1

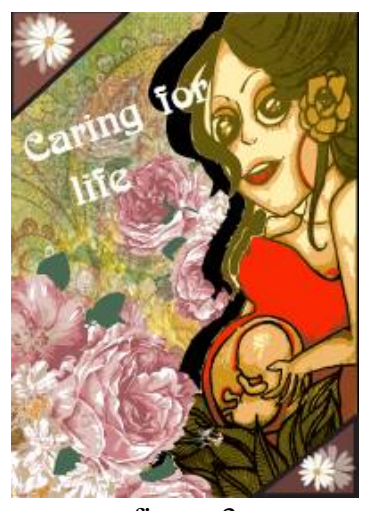

figure 3

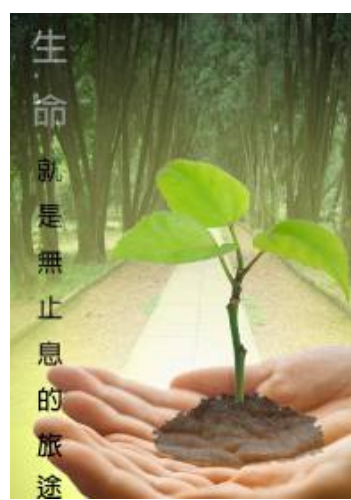

figure 2

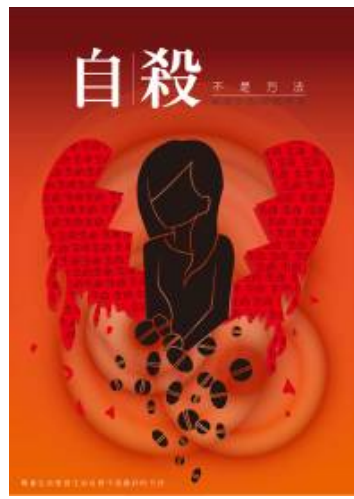

figure 4

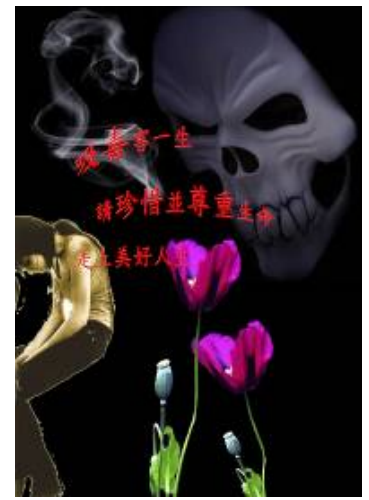

figure 5

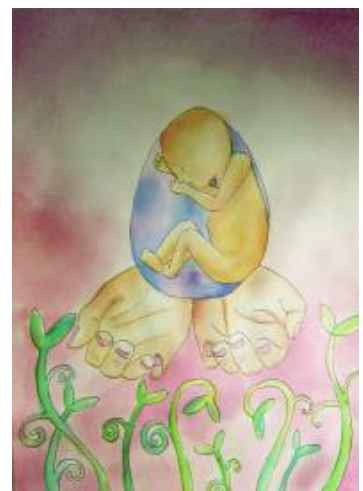

figure 7

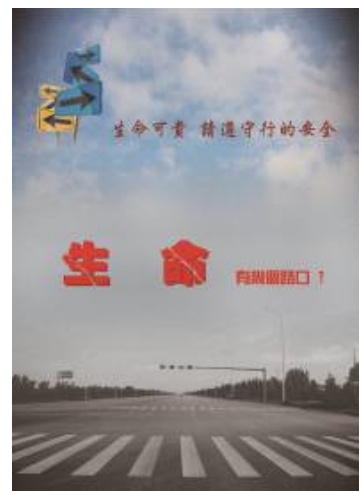

figure 9

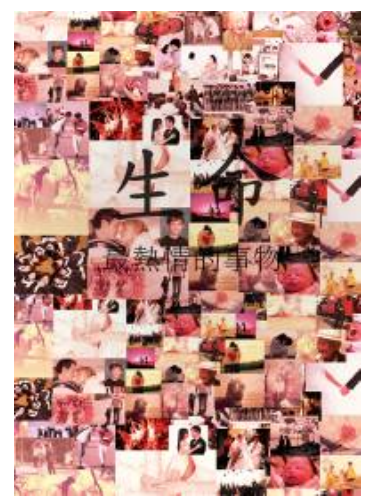

figure 11

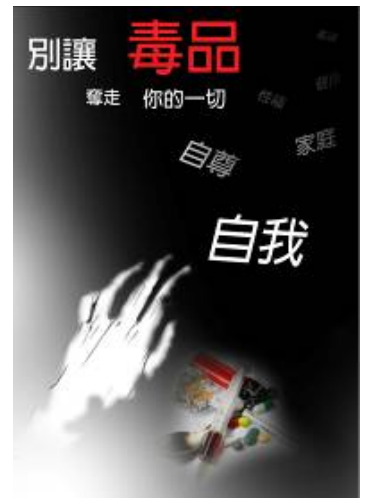

figure 6

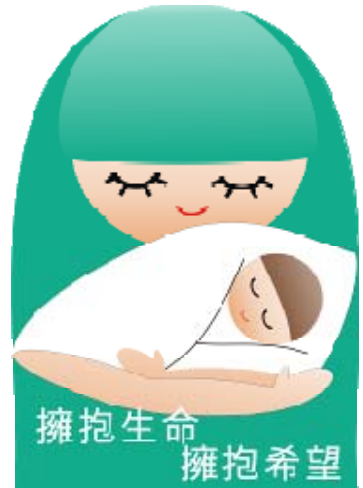

figure 8

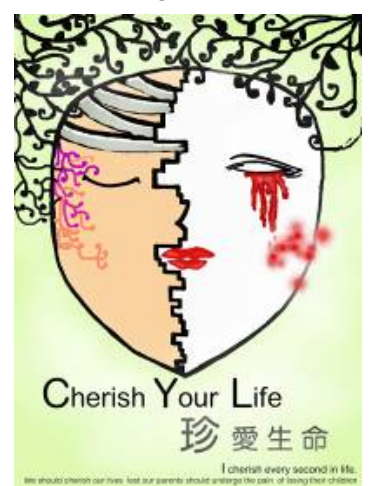

figure 10

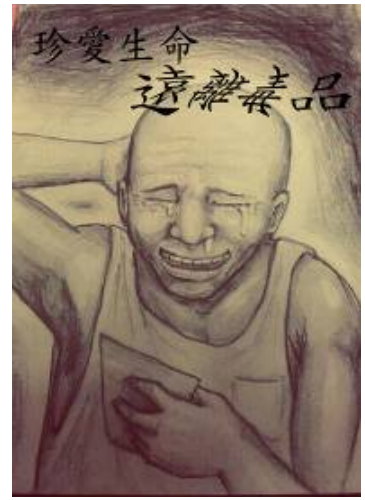

figure 12 


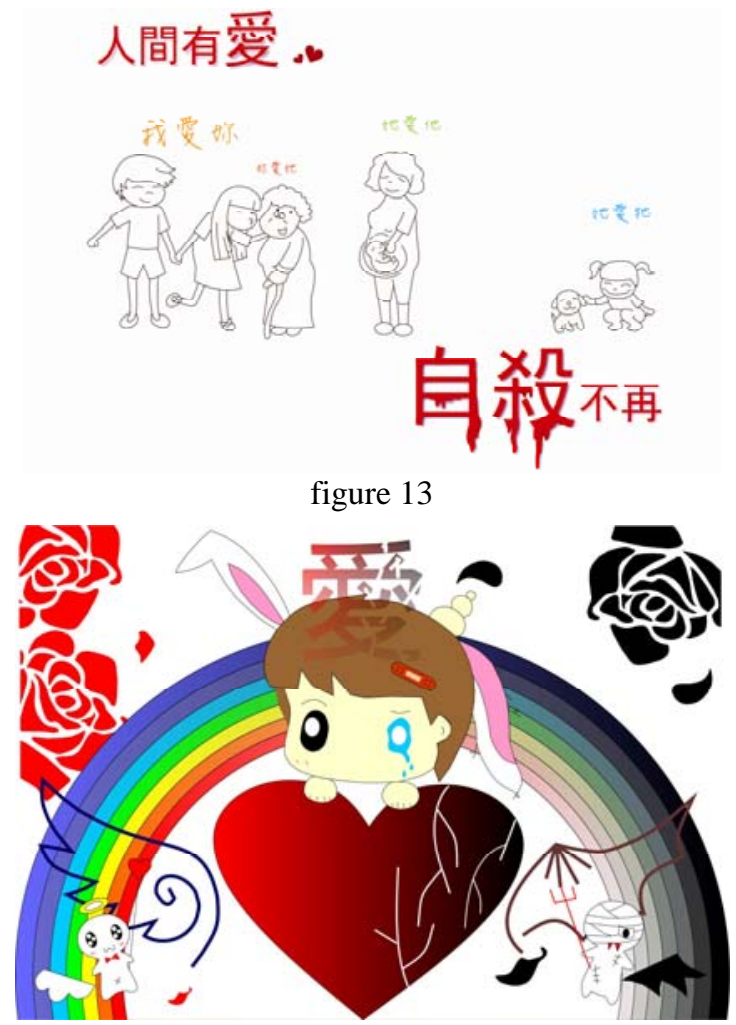

figure 14

\section{CONCLUSIONS}

\section{A. Discussions}

(1) Most students are not active in participating in design competitions. Therefore, teachers have to adopt various methods to stimulate their willingness to participate.

(2) Most professional teachers would integrate themes design competitions into curriculums as subjects for creative learning. And better works are selected to be submitted for competitions. Students can thus accumulate more competition experiences and their works can be refined.

(3) Awards won by teachers and students have positive influences on their departments' reputation. In the age of low birth rate, award winning records are essential to departments to recruit new students.

(4) Numbers of awards won by teachers and students are closely related to their schools' overall images and reputation. Especially, when schools apply for subsidies from the Ministry of Education and when they are evaluated, this number is a no doubt one of the important keys.

\section{B. Suggestions}

(1) Students should actively participate in design competitions held outside campuses and do their best. If there is sufficient time, students should consult their teachers or classmates more to make their works more completed, in order to increase their chances to win.

(2) When teachers integrate design competitions into their curriculums, they must consider whether competitions are proper and can match the curriculums. While encouraging students to participate in competitions, a communication mechanism between/among teachers should be built, in order to avoid situations of different classes participating in the same competitions.

(3) Department management should offer teachers and students who participate in competitions more recognition and administrative supports. And more positive rewards or prizes should be provided to winning teachers and students.

(4) Schools should come up with more incentive programs for honorable achievements of teachers and students, like offering monetary awards, to increase motivation and willingness of teachers and students to participate in competitions and increase numbers of awards won for the schools.

\section{REFERENCES}

[1] C. X. Ye, 2011, Educational Psychology, Psychological Publishing Co., Ltd., Taipei.

[2] F. T. He, Review of Life Education, Psychological Publishing Co., Ltd., Taipei, 2001.

[3] J. G. Wu, Life Education: Self-Awareness and Practices of Fusion of Horizons, Wunan Publishing Co., Ltd., Taipei, 2006.

[4] J. H. Guo, Life Education, Yang Zhi Publishing Co., Ltd., Taipei, 2002.

[5] L. A. Chen, 2008, Theories and Practices of Creative Thinking Teaching, Psychological Publishing Co., Ltd., Taipei.

[6] S. M. Lynch, Demography, Cohort and Life-course Patterns in the Relationship between Education and Health: A hierarchical approach, Demography, vol. 40, 2, May, 2003, pp. 309-331.

[7] S. Susan, Urban Design Education: learning for life in practice, Urban Design International, vol. 10, 1, April, 2005, pp. 3-10.

[8] W. Dong, W. Dong, J. Li, Life Safety Education in Secondary Physical Education for Unexpected Personal Injury Case, 2011 Third Pacific-Asia Conference on Circuits, Communications and System, 2011, pp. 1-3.

[9] X. B. Wu, Life Education Theories and Teaching Programs, Psychological Publishing Co., Ltd., Taipei, 2006.

[10] X. Tang, The Integration of Film Resources and College Students' Life Education, 2012 2nd International Conference on Consumer Electronics, Communications and Networks, 2012, pp. 3589-3591. 